\title{
A common language to assess allergic rhinitis control: results from a survey conducted during EAACI 2013 Congress
}

Peter W. Hellings ${ }^{1,2^{*}}$, Antonella Muraro ${ }^{3}$, Wytske Fokkens ${ }^{2}$, Joaquim Mullol ${ }^{4}$, Claus Bachert ${ }^{5}$, G. Walter Canonica ${ }^{6}$, David Price ${ }^{7}$, Nikos Papadopoulos ${ }^{8}$, Glenis Scadding ${ }^{9}$, Gerd Rasp ${ }^{10}$, Pascal Demoly ${ }^{11}$, Ruth Murray ${ }^{12}$ and Jean Bousquet ${ }^{13,14,15,16}$

\begin{abstract}
Background: The concept of control is gaining importance in the field of allergic rhinitis (AR), with a visual analogue scale (VAS) score being a validated, easy and attractive tool to evaluate AR symptom control. The doctors' perception of a VAS score as a good tool for evaluating AR symptom control is unknown, as is the level of AR control perceived by physicians who treat patients.

Methods: 307 voluntarily selected physicians attending the annual (2013) European Academy of Allergy and Clinical Immunology (EAACI) meeting completed a digital survey. Delegates were asked to (1) estimate how many AR patients/week they saw during the season, (2) estimate the proportion of patients they considered to have well-, partly- and un-controlled AR, (3) communicate how they gauged this control and (4) assess how useful they would find a VAS as a method of gauging control. 257 questionnaires were filled out completely and analysed.

Results: EAACl delegates reported seeing 46.8 [standard deviation (SD) 68.5] AR patients/week during the season. They estimated that $38.7 \%$ (SD 24.0), $34.2 \%$ (SD 20.2) and 20.0\% (SD 16.34) of their AR patients had well-controlled (no AR symptoms), partly-controlled (some AR symptoms), or un-controlled-(moderate/severe AR symptoms) disease despite taking medication [remainder unknown (7.1\%)]. However, AR control was assessed in many ways, including symptom severity (74\%), frequency of day- and night-time symptoms (67\%), activity impairment (57\%), respiratory function monitoring (nasal and/or lung function; $40 \%$ ) and incidence of AR exacerbations (50 \%). $91 \%$ of delegates felt a simple VAS would be a useful tool to gauge AR symptom control.
\end{abstract}

Conclusions: A substantial portion of patients with AR are perceived as having uncontrolled or partly controlled disease even when treated. A simple VAS score is considered a useful tool to monitor AR control.

Keywords: Allergic rhinitis, Control, Digital, Survey, Visual analogue scale, VAS

\section{Background}

Control of disease is considered one of the key outcomes in several medical domains. Although the concept of control is well-defined in asthma, chronic obstructive pulmonary disease and other conditions such as glycaemic control in diabetes, [1] it has only recently gained

\footnotetext{
*Correspondence: peter.hellings@med.kuleuven.be

${ }^{1}$ Department of Otorhinolaryngology, University Hospitals Leuven,

Leuven, Belgium

Full list of author information is available at the end of the article
}

significant attention in the field of allergic rhinitis (AR) [2-5]. Indeed, the patients' evaluation of disease control by any type of treatment, leading to a significant reduction of symptom severity, has become one of the novel goals of treatment in different chronic diseases. In AR, there is growing consensus that a visual analogue scale (VAS) score represents a simple, good and valid tool to monitor AR disease control [2, 6]. In 2010, Bousquet and colleagues [7] proposed a simple VAS to evaluate AR control. More sophisticated means of monitoring AR control have been used without showing superiority of one over the 
other [8]. Therefore, a VAS has been incorporated into the treatment algorithms for AR [2] to guide treatment decisions as part of an integrated care pathway [9]. It has yet to be validated in children. Nowadays, a digital version of the AR control VAS will be rolled out to patients, pharmacists and physicians to encourage better communication (with patients) and referral when appropriate. Physicians of all specialities involved in AR management can use the same VAS, from general practitioners (GPs) and allergists, to ear nose and throat (ENT) specialists, paediatricians, pulmonologists and dermatologists.

A VAS for AR has been shown to assess disease severity according to the Allergic Rhinitis and its Impact on Asthma (ARIA)-guidelines, with a VAS cut off score of $50 \mathrm{~mm}$ distinguishing between mild and moderate/severe AR in adults [10]. The VAS score incorporates quality of life (QoL) and reflective total nasal symptom score (rTNSS) [11] and correlates with improvements in AR symptoms and QoL. It can be used to assess AR severity in both intermittent and persistent disease in untreated or treated patients [10]. A change in VAS score of more than $23 \mathrm{~mm}$ represents clinically relevant changes in QoL and AR symptoms, possibly reflecting a response to treatment [6].

The major gaps in the current appreciation of VAS as a tool for the evaluation of symptom control are the following: (1) the level of control reached in patients by actual treatment options as perceived by the medical doctors, (2) how disease control is evaluated, and (3) physician perception on the usefulness of a VAS score for the evaluation of symptom control. Physicians often underestimate disease severity and impact on patients' lives, while at the same time over-estimate the effectiveness of treatment [12, 13]. Physician-patient communication is greatly hampered by a lack of a common language to describe AR control and a lack of a universally-accepted definition of what AR control actually means. The aim of this exploratory study was to assess how physicians measure AR symptom control, how they perceive the control status of their patients and how they regard the usefulness of a VAS to gauge disease control.

\section{Methods}

A quantitative, digital survey, designed to collect views of physicians who treat AR routinely in clinical practice, was carried out during the 32nd EAACI Congress (Milan, Italy) from 22nd to 26th June 2013. The survey content was informed by experts in the field of AR (JB, $\mathrm{CB}$ and DP) and conducted at the Meda booth by physicians attending the exhibition (see Additional file 1). There was no incentive to take part in the survey.

Those who consented to take part had their EAACI barcode scanned, were allocated a digital ID and were provided with the survey questions on an iPad. Responses to all questions were anonymised and stored on an independent server.

Delegates were asked to:

1. Estimate how many AR patients they saw per week during the season,

2. estimate the proportion of their patients they considered to have well-, partly- and un-controlled disease,

3. communicate how they gauged this control $(>1$ answer permitted)

4. assess how useful they would find a VAS as a method of gauging control.

A representation of a VAS with marker slider was shown to delegates when considering their response to question 4. Survey questions and representation of the VAS with marker slider are provided in Additional file 1.

Descriptive statistics (mean and standard deviation) were used to summarise survey responses.

\section{Results}

307 EAACI 2013 delegates from 60 different countries and from different specialties (e.g. GPs, allergists, ENT specialists and paediatricians) completed the survey. Valid question responses were obtained for 257 of these. Surveys from 50 delegates were not included as they were incomplete.

On average, respondents reported seeing 46.8 [standard deviation (SD) 68.5] AR patients/week during the season. They estimated that AR was well-controlled, partly-controlled and un-controlled in $38.7 \%$ (SD 24.0), $34.2 \%$ (SD 20.2) and $20.0 \%$ (SD 16.34) of patients, respectively, and unknown for the remainder (7.1\%). Delegates reported assessing disease control in many different ways, including symptom severity (74 \%), frequency of day- and night-time symptoms (67\%), activity impairment (57\%), respiratory function monitoring (nasal and/or lung function; $40 \%$ ) and incidence of AR exacerbations (50 \%) (Fig. 1). $91 \%$ of delegates felt that a VAS was a useful tool to assess disease control.

\section{Discussion}

According to 257 EACCI 2013 delegates, the VAS score is a useful tool to monitor disease control in AR. More than $50 \%$ of AR patients were considered by physicians to have partly-controlled or uncontrolled disease, with many different features of AR, unrelated to nasal symptoms, determining physicians' perception of disease of control. This observation that $>50 \%$ of their patients have sub-optimal AR control is in agreement with other surveys [13-15]. The physicians' perception of reaching a good level of control in $38.7 \%$ of patients also 


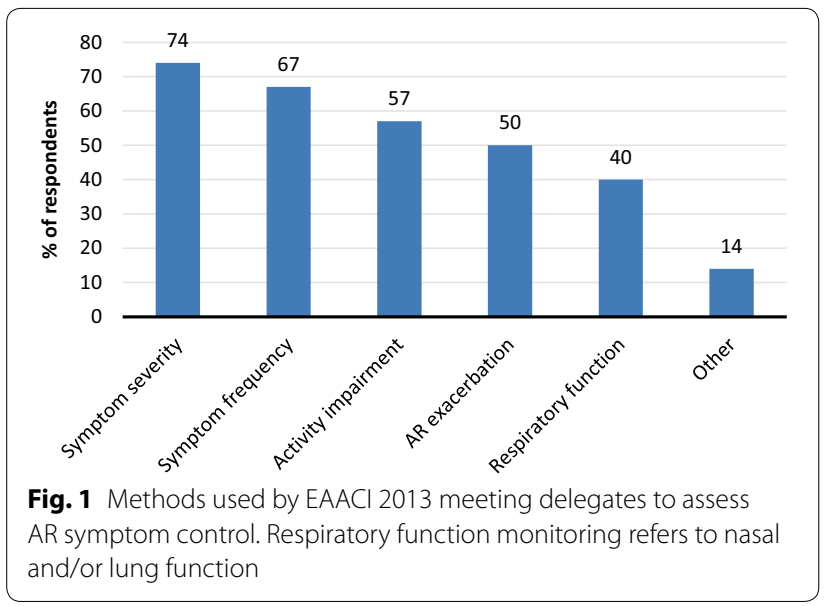

corresponds well with previous reports: A European survey found that, according to physician assessment, good control of nasal and ocular symptoms was achieved in 45.4 and $51.3 \%$ of patients, respectively [13].

It was also apparent that AR control was assessed in multiple ways with no consensus on an optimal method. Of note was the large standard deviation seen around control perception, which shows a wide-ranging response to the question. Interestingly, the determinants of control as perceived by the physicians varied from frequency of day- and night-time symptoms to respiratory function monitoring (nasal and/or lung function). One of the most striking findings was the extra-nasal symptoms, like frequency of day- and night-time symptoms and impaired activity being reported as key determinants of AR control.

$91 \%$ of the EAACI delegates who completed this survey agreed upon the validity of a VAS as a useful tool for assessing AR control. In our opinion, it is an intuitive tool for use in clinical studies, and by physicians and patients every day. The VAS is well suited to the task of assessing AR control. It is simple and quick to complete, incorporating assessment of both AR symptoms and quality-oflife [11]. It correlates well with recognized randomized controlled trial endpoints [16], can discriminate according to severity [10] and assess efficacy of treatments [16, 17]. The VAS has also been used to assess effectiveness of treatments in real-life [18] as well as inadequacies of others (including multiple treatments) [19].

Limitations of this survey relate to the fact that the most respondents were specialists (although with experience in treating AR), with relatively few GPs included. Delegates were not provided with an alternative control tool choice and also completed the survey at the Meda booth, which may have introduced bias. However, no financial or any other incentive was given to complete the survey. Also delegate speciality was not consistently recorded which may have yielded interesting insights into how AR control is assessed across specialities. Finally, information on what proportion of AR patients had concomitant asthma was not captured. This would have provided important information on how disease control was assessed and whether the perception of control was better or worse for those patients with co-morbid disease.

The VAS will form the basis of a new contre les MAladies Chronique pour un VIeillissement Actif (MACVIA)ARIA AR app directed at patients called 'Allergy Diary' which is now available for free download in many European countries. Users can assess their disease control daily by simply clicking on the VAS in response to the question 'overall how much are your allergic symptoms bothering you today?', from 'not at all bothersome' to 'extremely bothersome.' VAS scores are logged and plotted over time with control assessed as well-, partly- and un-controlled, according to specific VAS score cut-offs. The VAS will also be incorporated into a companion app for healthcare providers as well as into the new AR guideline, and used to guide treatment decisions. Moving to a digital VAS is attractive since in real life, on paper, VAS scores are often wrongly completed by the patient, even after explanation; either by failing to cross the line, putting a cross above or below it or writing a figure. An electronic version would prevent such errors. However, it may not allow for complexity of response such as persistence of a problematical co- morbidity despite good control of AR. The overall aim of 'Allergy Diary', the Allergy Diary companion app and the updated AR guideline (and the VAS contained within them) is to facilitate a top down communication, from guidelines to healthcare providers to patients, allowing doctors to more easily comply with the guidelines, to better tailor AR medications to patients' needs and enable patients to better communicate their needs.

In short, a common language of AR disease control is needed. A simple VAS to measure and assess disease control could meet this need and is welcomed by physicians. It should enable us to move from the illusion to the confirmation of communication.

\section{Additional file}

Additional file 1. Survey questions. The questions asked in a quantitative, digital survey carried out during the 32nd EAACI Congress (Milan, Italy) from 22nd to 26th June 2013.The survey was designed to collect views of physicians who treat AR routinely in clinical practice. It includes a representation of a VAS with maker slider that was shown to delegates when considering their response to question 9 of the survey. 


\section{Abbreviations}

AR: allergic rhinitis; ARIA: allergic rhinitis and its impact on asthma; EAACl: European Academy of Allergy and Clinical Immunology; ENT: ear nose and throat; GP: general practitioner; MACVIA: Contre les MAladie Chronique pour un Vleillissement Actif; QoL: quality of life; rTNSS: reflective total nasal symptom score; SD: standard deviation; VAS: visual analogue scale.

\section{Authors' contributions}

All authors have been involved in the analysis and interpretation of data. JB, $\mathrm{CB}$ and DP also designed and approved the content of the questionnaire for the physicians. All authors were involved in the drafting of the manuscript, critically revised each draft and gave their final approval for publication. All authors agree to be accountable for all aspects of this work and have participated sufficiently to take public responsibility for the content. All authors read and approved the final manuscript.

\section{Authors' information}

$\mathrm{PH}$ is a rhinologist and allergologist, working in the University Hospitals of Leuven, and Academic Medical Center, Amsterdam, and leading a research team on upper airways inflammation at the University of Leuven. He is the current Secretary-General of EAACI (2015-2017). AM is a Consultant Paediatric Allergist at the Department of Women and Child Health, Padua University Hospital, Italy and Professor of Paediatric Allergology at the Allergy and Clinical Immunology School, University of Padua. She was Secretary General of EAACI from 2013 to 2015 and is the current President of EAACI (2015-2017). WF is an otorhinolaryngologist and head of the department of Otorhinolaryngology of the Academic Medical Centre Amsterdam. JM is an ENT specialist and Director of the Rhinology Unit and Smell Clinic, ENT Department, Hospital Clínic de Barcelona; and Professor of Research and Head of the Laboratory Clinical and Experimental Respiratory Immunoallergy at IDIBAPS, Barcelona, Catalonia, Spain. CB is ENT specialist and allergologist at the Ghent University Hospital, and runs the Upper Airways Research Laboratory, Ghent University. He also is affiliated with the Karolinska Institute in Stockholm, Sweden. GWC is Professor of Respiratory Medicine and Director of Allergy \& Respiratory Disease Clinic, Dept Internal Medicine, University of Genoa, IRCCS AOU San Martino, Genoa Italy. DP is Professor of Primary Care Respiratory Medicine at the University of Aberdeen, co-founder of the Respiratory Effectiveness Group (http://www. effectivenessevaluation.org) and Director of Observational and Pragmatic Research Institute, Singapore. NP is Professor of Allergy and Paediatric Allergy at the Universities of Manchester, UK and Athens, Greece. GS is Hon. Consultant Rhinologist and Allergist at the Royal National TNE Hospital, London and Hon. Senior Lecturer at University College, London. GR is Professor for Otorhinolaryngology and Chairman of the ORL-Department at the Paracelsus Medical University Salzburg, Austria. PD is a pulmonologist and allergist, Professor of Pulmonology and Head of Department at the University Hospital of Montpellier. He was the Vice-President for Education and Specialties of EAACl from 2011 to 2015 and President of the French Allergy Society from 2010 to 2012. In addition, PD is Associate Editor of the journal ALLERGY, is a member of the editorial board of several national and international medical allergy journals and is a member of the French National Academy of Medicine. RM is the director of a Medical and Scientific research consultancy. JB is a Professor Emeritus at the University of Montpellier in France. He is recognized as past chairman of the Global Initiative for Asthma (GINA) and as the founder and Chairman of ARIA (Allergic Rhinitis and its Impact on Asthma), in collaboration with the World Health Organization. Prof Bousquet is also past Chairman of the WHO Global Alliance Against Chronic Respiratory Diseases (GARD), Director of the WHO Collaborating Centre for Asthma and Rhinitis in Montpellier, and coordinator of several projects of the European Union in research, health and ICT. Professor Bousquet's current interests lie with the European Innovation Partnership on Active and Health Aging, and updating how chronic diseases like allergic rhinitis are managed using an integrated care pathway.

\section{Author details}

${ }^{1}$ Department of Otorhinolaryngology, University Hospitals Leuven, Leuven, Belgium. ${ }^{2}$ Department of Otorhinolaryngology, Academic Medical Center (AMC), Amsterdam, The Netherlands. ${ }^{3}$ Department of Women and Child Health, Food Allergy Referral Centre, Padua University Hospital, Veneto Region, Padua, Italy. ${ }^{4}$ Hospital Clinic, IDIBAPS, CIBERES, Barcelona, Catalonia, Spain.

${ }^{5}$ Upper Airways Research Laboratory (URL), University Hospital Ghent, Ghent, Belgium. ${ }^{6}$ Allergy and Respiratory Diseases, Department of Internal Medicine, IRCCS S Martino, IST, University of Genoa, Genoa, Italy. ${ }^{7}$ Centre of Academic
Primary Care, University of Aberdeen, Aberdeen, UK. ${ }^{8}$ Allergy Department, 2nd Pediatric Clinic, University of Athens, Athens, Greece. ${ }^{9}$ RNTNE Hospital, London, UK. ${ }^{10}$ Department of Otorhinolaryngology, Paracelsus Medical University, Salzburg, Austria. ${ }^{11}$ Division of Allergy, Department of Pulmonology, Hôpital Arnaud de Villeneuve, University Hospital of Montpellier, Montpellier, France. ${ }^{12}$ MedScript Ltd, Dundalk, Co. Louth, Ireland. ${ }^{13}$ University Hospital, Montpellier, France. ${ }^{14}$ MACVIA-LR, Contre les Maladies Chronique pour un Vieillissement Actif en Languedoc Roussilon, European Innovation Partnership on Active and Healthy Aging Reference Site, Montpellier, France. ${ }^{15}$ INSERM, VIMA: Ageing and Chronic Diseases. Epidemiological and Public Health Approaches, U1168 Paris, France. ${ }^{16}$ UVSQ UMR-S1 168, Universite Versailles St-Quentin-en-Yvelines, Versailles, France.

\section{Acknowledgements}

We thank EAACI for allowing this survey to be conducted during the 32nd annual meeting in Milan, 2013.

\section{Competing interests}

$\mathrm{PH}$ has received research grants and/or has been lecturing for GSK, Merck, Stallergenes and ALK. AM has provided educational lectures for Meda and Allergopharma. WF has received an educational grant from Meda and research grants from GSK and Biopharma. JM is or has been member of national and international scientific advisory Boards (consulting), received fees for lectures, or grants for research projects from ALK-Abelló, Boheringer-Ingelheim, Crucell, Esteve, FAES, GSK, Hartington Pharmaceuticals, Johnson and Johnson, MEDA Pharma, MSD, Novartis, Pierre Fabre, Sanofi-Aventis, Schering Plough, UCB, Uriach Group, Zambon. CB on the speaker's bureau for Meda. GWC has received honoraria for lectures or scientific advisory boards: ALK, Allergy Therapeutics, AstraZeneca, Boston Scientific, Bruschettini, Chiesi, Circassia, Faes, GSK, Meda, Menarini, Mundifarma, Novartis, Recordati, Roche, Sanofi-Aventis, Uriach, Stallergènes, Thermo Fisher, Teva, Valeas. DP has Board Membership with Aerocrine, Almirall, Amgen, AstraZeneca, Boehringer Ingelheim, Chiesi, Meda, Mundipharma, Napp, Novartis, and Teva. Consultancy: A Almirall, Amgen, AstraZeneca, Boehringer Ingelheim, Chiesi, GlaxoSmithKline, Meda, Mundipharma, Napp, Novartis, Pfizer, and Teva; Grants and unrestricted funding for investigator-initiated studies from UK National Health Service, British Lung Foundation, Aerocrine, AKL Ltd, Almirall, AstraZeneca, Boehringer Ingelheim, Chiesi, Eli Lilly, GlaxoSmithKline, Meda, Merck, Mundipharma, Napp, Novartis, Orion, Pfizer, Respiratory Effectiveness Group, Takeda, Teva, and Zentiva; Payments for lectures/speaking: Almirall, AstraZeneca, Boehringer Ingelheim, Chiesi, Cipla, GlaxoSmithKline, Kyorin, Meda, Merck, Mundipharma, Novartis, Pfizer, SkyePharma, Takeda, and Teva; Payment for manuscript preparation: Mundipharma and Teva; Patents (planned, pending or issued): AKL Ltd.; Payment for the development of educational materials: GlaxoSmithKline, Novartis; Stock/Stock options: Shares in AKL Ltd which produces phytopharmaceuticals and owns $80 \%$ of Research in Real Life Ltd and its subsidiary social enterprise Optimum Patient Care; received Payment for travel/accommodations/meeting expenses from Aerocrine, Boehringer Ingelheim, Mundipharma, Napp, Novartis, and Teva; Funding for patient enrolment or completion of research: Almirral, Chiesi, Teva, and Zentiva; and Peer reviewer for grant committees: Medical Research Council (2014), Efficacy and Mechanism Evaluation programme (2012), HTA (2014). NP has received grants from GSK, Nestle and Merck, provided consultancy to GSK, Abbvie, Novartis, Menarini, Meda, and Alk-Abello, is on the speakers bureau for Novartis, Allegopharma, Uriach, GSK, Stallergens and MSD and provided educational presentations for Abbvie, Sanofi and Meda. GS has received research grants from GSK and ALK as well as honoraria for articles, consulting, lectures/chairing and/or advisory boards from ALK, Bausch and Lomb, Church and Dwight, Circassia, GSK, Groupo Uriach, Meda, Merck, Ono, Shionogi and Stallergenes. GR has received honoraria for consulting/lectures/ chairing/advisory boards from ALK, Allergopharma, GSK, Meda, MSD, Novartis, Stallergenes, Sanofi-Aventis. PD is a consultant (and a speaker) for Stallergenes, Circassia, ALK, DBV and Chiesi and was a speaker for Merck, Astra Zeneca, Pierre Fabre Médicaments, Menarini, Allergopharma, Allergy Therapeutics Ltd., ThermoFischer Scientific and GlaxoSmithKline. RM is the director of a Medical and Scientific Affairs consultancy which has provided consultancy services to Meda, MACVIA ARIA and RIRL. JB has received honoraria for: Scientific and advisory boards_-Almirall, Meda, Merck, MSD, Novartis, Sanofi-Aventis, Takeda, Teva, Uriach. Lectures during meetings_-Almirall, AstraZeneca, Chiesi, GSK, Meda, Menarini, Merck, MSD, Novartis, Sanofi-Aventis, Takeda, Teva, Uriach. Board of Directors_-Stallergènes. 
Received: 31 July 2015 Accepted: 23 September 2015

Published online: 27 October 2015

\section{References}

1. Fullerton B, Jeitler K, Seitz M, Horvath K, Berghold A, Siebenhofer A. Intensive glucose control versus conventional glucose control for type 1 diabetes mellitus. Cochrane Database Syst Rev. 2014;2:CD009122.

2. Hellings PW, Fokkens WJ, Akdis C, Bachert C, Cingi C, Dietz de Loos D, et al. Uncontrolled allergic rhinitis and chronic rhinosinusitis: where do we stand today? Allergy. 2013;68:1-7.

3. Mullol J, Bartra J, Del CA, Izquierdo I, Munoz-Cano R, Valero A. Specialistbased treatment reduces the severity of allergic rhinitis. Clin Exp Allergy. 2013:43:723-9.

4. Fonseca JA, Nogueira-Silva L, Morais-Almeida M, Sa-Sousa A, Azevedo LF, Ferreira J, et al. Control of Allergic Rhinitis and Asthma Test (CARAT) can be used to assess individual patients over time. Clin Transl Allergy. 2012;2:16.

5. Linhares DV, da Fonseca JA, Borrego LM, Matos A, Pereira AM, Sa-Sousa A, et al. Validation of control of allergic rhinitis and asthma test for children (CARATKids) - a prospective multicenter study. Pediatr Allergy Immunol 2014;25:173-9.

6. Demoly P, Bousquet PJ, Mesbah K, Bousquet J, Devillier P. Visual analogue scale in patients treated for allergic rhinitis: an observational prospective study in primary care: asthma and rhinitis. Clin Exp Allergy. 2013:43:881-8.

7. Bousquet PJ, Bachert C, Canonica GW, Casale TB, Mullol J, Klossek JM, et al. Uncontrolled allergic rhinitis during treatment and its impact on quality of life: a cluster randomized trial. J Allergy Clin Immunol. 2010;126:666-8.

8. Demoly P, Calderon MA, Casale T, Scadding G, Annesi-Maesano I, Braun J J, et al. Assessment of disease control in allergic rhinitis. Clin Transl Allergy. 2013;3:7.
9. Bousquet J, Addis A, Adcock I, Agache I, Agusti A, Alonso A, et al. Integrated care pathways for airway diseases (AIRWAYS-ICPS). Eur Respir J. 2014;44:304-23

10. Bousquet PJ, Combescure C, Neukirch F, Klossek JM, Mechin H, Daures JP, et al. Visual analog scales can assess the severity of rhinitis graded according to ARIA guidelines. Allergy. 2007;62:367-72.

11. Bousquet PJ, Combescure C, Klossek JM, Daures JP, Bousquet J. Change in visual analog scale score in a pragmatic randomized cluster trial of allergic rhinitis. J Allergy Clin Immunol. 2009;123:1349-54.

12. Meltzer EO. Allergic rhinitis: the impact of discordant perspectives of patient and physician on treatment decisions. Clin Ther. 2007;29:1428-40.

13. Canonica GW, Bousquet J, Mullol J, Scadding GK, Virchow JC. A survey of the burden of allergic rhinitis in Europe. Allergy. 2007;62(Suppl 85):17-25.

14. Keith PK, Desrosiers M, Laister T, Schellenberg RR, Waserman S. The burden of allergic rhinitis (AR) in Canada: perspectives of physicians and patients. Allergy Asthma Clin Immunol. 2012;8:7.

15. Fromer LM, Ortiz G, Ryan SF, Stoloff SW. Insights on allergic rhinitis from the patient perspective. J Fam Pract. 2012;61:S16-22.

16. Bousquet J, Bachert C, Canonica GW, Mullol J, Van CP, Bindslev-Jensen C, et al. Efficacy of desloratadine in intermittent allergic rhinitis: a GA(2)LEN study. Allergy. 2009;64:1516-23.

17. Bousquet J, Bachert C, Canonica GW, Mullol J, Van CP, Bindslev-Jensen C, et al. Efficacy of desloratadine in persistent allergic rhinitis-a GA(2)LEN study. Int Arch Allergy Immunol. 2010;153:395-402

18. Klimek L, Bachert C, Mosges R, Munzel U, Price D, Virchow JC, et al. Effectiveness of MP29-02 for the treatment of allergic rhinitis in real-life: results from a noninterventional study. Allergy Asthma Proc. 2015;36:40-7.

19. Bousquet PJ, Demoly P, Devillier P, Mesbah K, Bousquet J. Impact of allergic rhinitis symptoms on quality of life in primary care. Int Arch Allergy Immunol. 2013;160:393-400

\section{Submit your next manuscript to BioMed Central and take full advantage of:}

- Convenient online submission

- Thorough peer review

- No space constraints or color figure charges

- Immediate publication on acceptance

- Inclusion in PubMed, CAS, Scopus and Google Scholar

- Research which is freely available for redistribution

Submit your manuscript at

www.biomedcentral.com/submit

C Biomed Central 